\section{MS14-P19 Artificial coral reefs, electrochemistry and calcium carbonate: electrodeposited coral-like aragonite}

Cosmelina Gonçalves Da Silva ${ }^{1}$, Dang Dan Nguyen ${ }^{1}$, Alaric Zanibellato $^{2}$, Charlotte Carré, 2,3 , Otavio Gil ${ }^{1}$, Marc Jeannin ${ }^{2}$, René Sabot $^{2}$, Arnaud Serres ${ }^{3}$, Peggy Gunkel Grillon ${ }^{3}$, Nicolas Verjat ${ }^{4}$, Brahim Benaissa ${ }^{4}$, Stéphanie Gascoin ${ }^{1}$, Richard Retoux ${ }^{1}$, Magali Morales $^{5}$, Benoit Riffault ${ }^{1}$, Daniel Chateigner ${ }^{1}$

1. CRISMAT, ABTE, IUT, Université Caen Basse Normandie, France

2. LASIE, Univ La Rochelle, France

3. PPME, Univ. Nouvelle Calédonie

4. Géocorail SAS, Paris

5. CIMAP, Université de Caen Basse Normandie, France

email: daniel.chateigner@unicaen.fr

Global warming's largest influence on coastal ranges remains massive erosion. Artificial reinforcements often suffer instable basements, in particular on large and sandy beaches. One potentially large-scale approach to consolidate such coasts rely in the use of electrodeposition of conglomerates of calcium carbonate, substituting the weak mechanical loci, at no environmental cost.

In this approach, natural sea-water provides the necessary elements $\left(\mathrm{Ca}\right.$ and $\mathrm{CO}_{2}$ ) for the precipitation of calcium carbonate around the working electrode that can be easily adapted to the local geometry, with no a priori limit in scale (Géocorail $\AA$ ).

The calcium carbonate deposits on metallic electrodes and on extended regions around them, ages and creates bonds between mineral sediments coming from sea waves carriage, and then makes a mechanically resistant agglomerate "Géocorail". The deposited calcium carbonate is the aragonite polymorph, one of the most present biominerals in the oceans, in mollusc shells and corals. It is then important to compare our Géocorail with biominerals in order to optimize our elaboration process for eventual neo-fauna colonisation of the reinforcements.

In this work, we selected few dead specimen of coral species from Noumea, Nouvelle Calédonie, Cancun, Mexico and Saint François, Guadalupe, and compared them with the artificially grown electrochemical samples, with the help of x-ray diffraction and SEM imaging.

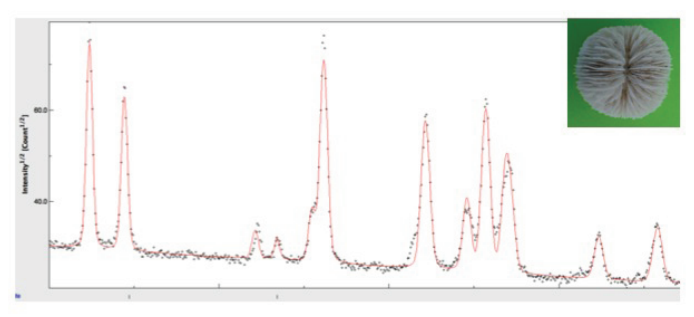

Figure 1. X-ray diffraction pattern of one lamellae of Fungia fungites (Noumea)
Keywords: aragonite, coral, electrochemistry, artificial coral reef, calcium carbonate 